\title{
OS BACHARÉIS NA POLÍTICA NACIONAL DURANTE AS DUAS DEMOCRACIAS ${ }^{12}$
}

\author{
Mariana Arcos Lorencetti ${ }^{3}$
}

\section{RESUMO}

Dentre aqueles de profissão tradicional na política, relevantes em parlamentos e em tantos outros postos políticos, temos os advogados. Este texto presume a necessidade de descrever, definir e ilustrar uma possível diferenciação interna desse grupo, tomando como base os advogados-deputados do período de 1945 a 1962 e de 1986 a 2010. Tal pesquisa se deu mediante o uso da Análise de Correspondência Múltipla, com a formação de planos visuais nos quais se aproximam características em casos de ocorrência concomitante, tomando variáveis de ordem socioprofissional e política como base. Os resultados nos mostram que a ideologia está relacionada a determinados subgrupos de exercício profissional e que a duração e o prestígio das carreiras dependem de um início precoce na vida pública.
\end{abstract}

Palavras-chave: Advogados. Deputados. Elites.

\begin{abstract}
Amongst those in politics who are professionals from "traditional" occupations, common in parliaments and other political positions, there are the lawyers, segment which makes up a relevant portion of this group. This article presumes that there is a necessity of describing and sketching a possible internal diversity in that professional group, having as a model those who held office in the Federal Chamber of Deputies on both democratic periods in Brazil (1945-1962 and 1986-2010). The analysis was made by using Multiple Correspondence Analysis, which creates graphic representations of occurrences and tendencies, having in mind variables of socioprofessional and political nature. Our results show that ideology has an affinity with certain subgroups of professionals and that the length or notoriety of a career is linked to an early entrance in the political field.
\end{abstract}

Keywords: Lawyers. Elites. Deputies.

\section{RESUMEN}

Entre las tradicionalmente relevantes profesiones en la política, en los parlamentos y en tantos otros puestos políticos, contamos con abogados. Este texto supone la necesidad de describir y definir a este grupo y ilustrar una posible diferenciación interna, basada en los abogados diputados en los periodos de 1945-1962 y de 1986-2010. Este proceso se produce mediante el uso de Análisis de Correspondencias Múltiples, con planes para abordar características visuales en caso de ocurrencia concomitante, tomando variables de orden socioprofesional y política. Los resultados nos muestran que la ideología está relacionada a ciertos subgrupos inclusos en la misma división profesional y que la duración y el prestigio de una carrera dependen sobre todo de la entrada temprana en ella.

Palabras clave: Abogados. Diputados. Las élites.

\section{INTRODUÇÃO}

Este trabalho analisa a advocacia como uma profissão compatível com a política em diversos âmbitos. Podemos considerá-la como uma ocupação cuja forma é semelhante à da prática política, com suas negociações, contatos com o meio público, modos de ação, saberes e recursos convergentes (EULAU; SPRAGUE, 1964), também sendo possível considerar a

\footnotetext{
${ }^{1}$ Submetido em: 13 de Agosto de 2017. Aprovado em: 09 de Outubro de 2017.

2 DOI: http://dx.doi.org/10.5380/recp.v8i3.54505

${ }^{3}$ Mariana Arcos Lorencetti é graduada em Ciências Sociais na Universidade Federal do Paraná (UFPR) e Mestra em Ciência Política na mesma universidade. Contato da autora: malorencetti@gmail.com.
} 
profissão liberal jurídica como provedora de recursos que podem ser convertidos em vantagem na corrida eleitoral (CODATO; COSTA; MASSIMO, 2014; RODRIGUES, 2006).

Outra razão que faz o grupo analisado objeto de estudo relevante para a Ciência Política, mesmo em relação a outras profissões, é o número sempre expressivo - ainda que decrescente - de advogados na Câmara nacional. Tomando aqueles que possuem o Direito como formação superior e a advocacia como qualquer uma de suas profissões declaradas, temos $17,52 \%$ de todos os deputados do período entre 1945 e 2010 - sendo que, de forma mais precisa, os advogados foram 22,92\% dos Deputados Federais entre 1945 e 1962 e 12,13\% quando considerado o intervalo entre 1986 e 2010, os dois períodos estudados neste trabalho.

O propósito deste trabalho é descrever a profissão dos advogados na política, tomando como base as trajetórias de indivíduos que declararam ter tal profissão e ocuparam um posto na Câmara dos Deputados entre 1945 e 1962 e entre 1986 e 2010. Aqui, propõe-se pensar três questões gerais: em primeiro lugar, como profissões e variáveis políticas podem ser influenciadas mutuamente; em segundo lugar, como as "maneiras de ser advogado" são modificadas pelo tempo; e, em terceiro, como uma "profissão da política" — ou seja, uma profissão que gera pessoal para quadros políticos e cujas práticas possuem natureza interseccional — pode se mostrar como exercício profissional prévio à entrada no cargo público ou como identidade influente nos perfis sociopolíticos. São utilizadas variáveis relativas à extensão das carreiras políticas, à permanência na Câmara, às posições de liderança na Casa, à ideologia partidária, à formação profissional e aos tipos de prática profissional dos advogados.

\section{JUSTIFICATIVA, DEFINIÇÕES E HIPÓTESE}

Duas justificativas são essenciais para o estabelecimento deste trabalho: por que escolhemos o estudo das profissões e o porquê da escolha desta profissão específica. Faz-se necessário circundar diversos tipos de estudos para responder a estas questões. Partimos do princípio de que aqueles eleitos não formam um grupo que espelha aqueles que os elegeram (DOGAN, 1999, p. 171); em seguida, tomamos os estudos de recrutamento, que alegam existirem "vantagens" em se exercer determinados ofícios em detrimento de outros, seja pela possibilidade de se ter tempo livre (PERISSINOTTO; MIRÍADE, 2009), seja pelo encontro de práticas, discursos ou retórica (BOURDIEU, 1998; DOGAN, 1999; EULAU; SPRAGUE, 1964). Logo, podemos alegar a importância da profissão como variável, bem como pensar uma profissão em detrimento de outras. No entanto, é importante lembrar que, apesar de emprestados estes pressupostos e achados de estudos de recrutamento, estamos lidando com um grupo de 
pessoas eleitas, de forma que se deve complementar tais possíveis explicações com dois pontos: as mudanças no meio político e as do meio profissional.

O conceito de "profissão" deve ser definido de modo a justificar o recorte e a escolha dos casos estudados. Seu sentido, conforme empregado aqui, está intimamente ligado à noção do título como diferencial na sociedade, à atribuição do prestígio correspondente a ele e à noção de rótulo. Indo além de uma explicação ligada ao saber técnico que atribui autoridade (PARSONS, 1967, p. 38), a profissão modifica as relações sociais nas quais o indivíduo se insere. É, de forma concisa, um conjunto de relações sociais combinadas a um dado status (EULAU; SPRAGUE, 1964); mais abstratamente, a profissão está dissociada até mesmo do ganho financeiro: vai muito além de ocupar certo posto de trabalho (BOURDIEU, 2011).

Primeiramente, deve ser dito que as profissões não são as mesmas ao longo do tempo (OFFERLÉ, 1999, p. 20), e que um único meio ocupacional pode abranger diferentes atuações, conforme alega Karpik (1985) a respeito dos advogados franceses. É desta forma que pensamos os advogados brasileiros, cuja atuação possui um posicionamento social e político passível de transição. Inicialmente, podemos citar o "ingresso automático às elites" proporcionado pela formação no Brasil império (BARMAN; BARMAN, 1976; CARVALHO, 1982; DEZALAY; GARTH, 2000), seguido pela formação para o funcionalismo público em quadros do Estado (ALMEIDA, 2010a) e, posteriormente, nas décadas de 80 e 90, pelo crescimento vertiginoso dos cursos de Direito, direcionados para uma profissão que visava o lucro e o profissionalismo liberal como prioridade (ALMEIDA, 2010a), bem como, pode-se alegar, a criação de uma massa de novos "proletários de gravata" (SADEK, 2004).

O meio político também sofre mutações ininterruptas. Podemos citar o decrescimento do número de advogados na política, tendência vinda desde os primórdios da República, quando esse grupo, primariamente preferido para os cargos políticos (ALMEIDA, 2010b; BARMAN; BARMAN, 1976; BONELLI, 2003; CARVALHO, 2008), passa a dividir progressivamente seu espaço com médicos e engenheiros (CARVALHO, 1982; VENANCIO, 2004) e, em tempos recentes, com outras camadas sociais e profissionais (RODRIGUES, 2006). A própria transição entre jurismo e política toma outra face quando se pensa que, com a profissionalização política, a questão de "ser jurista ou político primeiro" (SADEK; DANTAS, 2000) passa a ser um conflito plausível.

Desta forma, este trabalho oferece as seguintes hipóteses: a principal, de que não existe uma forma única de "ser advogado na política", sendo que os moldes desse exercício modificam-se conforme o contexto histórico e o período; a de que é esperado que a relação do indivíduo com sua profissão exerça influência sobre sua carreira política, estando inclusas nessa 
equação as áreas em que um indivúduo atuou no interior da profissão e por quanto tempo advogou; e a de que espera-se que diferentes tipos de advogado possuam diferentes tipos de atuação e de carreira política.

\section{PORMENORES METODOLÓGICOS: FONTES, NÚMERO DE CASOS E RECORTE}

Nas coletas de dados, coordenadas pelo Núcleo de Pesquisa em Sociologia Política Brasileira da Universidade Federal do Paraná (NUSP/UFPR), foram utilizados como fonte o site oficial da Câmara dos Deputados e o Dicionário Histórico-Biográfico Brasileiro (DHBB). Considerando-se que os registros da Câmara dos Deputados (CD) se iniciam na $41^{\mathrm{a}}$ Legislatura, todos os casos anteriores a ela foram unicamente coletados no DHBB.

A pesquisa original contou com 7212 casos correspondentes a cada mandato de cada parlamentar do período. No entanto, esse número de casos foi filtrado por uma série de critérios. Após o recorte que selecionou os mandatos apenas daqueles declarados advogados, foram contabilizados 1349 casos. Contudo, com a opção de não incluir repetições na amostra, de forma a considerar os indivíduos e não os seus mandatos como unidade de análise ${ }^{4}$ e de excluir o período compreendido entre 1966 e 1982 para comparação apenas dos momentos democráticos nacionais, foi possível chegar ao número de 491 casos. Aqui, chamamos "advogado" aquele que: a) declarou a advocacia como qualquer uma de suas profissões, conforme consta na página online da Câmara dos Deputados (mesmo aqueles que exercem mais de uma profissão ou outra profissão principal serão considerados); e b) foi definido como advogado em biografia, ainda que não o fosse exclusivamente ou de forma central, conforme texto apresentado no Dicionário Histórico-Biográfico Brasileiro.

Os períodos analisados são a República Populista (legislaturas de 1945 a 1962) e a Nova República (legislaturas de 1986 a 2010), e as variáveis da pesquisa são as apresentadas a seguir.

\footnotetext{
${ }^{4}$ Opção que faz sentido tendo em vista a possibilidade de reeleição para o cargo de deputado.
} 


\section{VARIÁVEIS DE ANÁLISE}

É necessário que se explique, inicialmente, que o banco de dados que deu origem a este trabalho contava com duas variáveis, que foram então unificadas: as variáveis "tempo de exercício profissional" e "esferas de atuação profissional". Estas mensuravam inicialmente o tempo entre a obtenção do diploma e a entrada no meio político, se o indivíduo declarou ou teve mais profissões e, se teve ou declarou, quais foram essas profissões — além da advocacia. Tais variáveis foram unificadas em "tipo de atuação profissional", e as razões para tal são melhor explicadas a seguir.

Foi encontrado significativo índice de correlação entre as duas variáveis - mais precisamente, detectou-se que aqueles envolvidos em mais de uma profissão jurídica (e apenas profissões jurídicas) exerciam a profissão por mais tempo do que suas contrapartes, enquanto aqueles que tiveram mais de uma profissão além de advogado e os advogados "puros" se dividiam entre as demais categorias de tempo de carreira profissional.

Também foi utilizado como base o trabalho de Almeida (2016) que separa as categorias de parlamentares formados em Direito entre "bacharéis políticos" e "políticos juristas". Tais categorias foram aceitas aqui com uma ressalva: notamos diferenciações entre aqueles que foram apenas advogados, aqueles unicamente do meio jurídico e aqueles com múltiplas profissões. Em consequência disso, a partir de observação empírica do banco de dados aqui utilizado, a nova variável foi codificada de outra maneira. Aqueles que se formaram após a entrada na política ou exerceram sua profissão por pouquíssimo tempo foram considerados "políticos bacharéis"; aqueles que atuaram no campo jurídico de diversas formas foram denominados "juristas"; advogados com longo tempo de atuação profissional receberam o rótulo de "advogados"; e, por fim, aqueles que exerceram múltiplas profissões não relacionadas entre si por um certo tempo, tendo a advocacia como um título adicional, foram chamados apenas de "bacharéis". Tal categorização pode ser vista na Tabela 1: 
TABELA 1 - DEFINIÇÃO DA VARIÁVEL “TIPO DE TRAJETÓRIA PROFISSIONAL”

\begin{tabular}{c|c|c}
\hline Categoria & Tipo de atuação & Tempo de atuação \\
\hline $\begin{array}{c}\text { Políticos } \\
\text { bacharéis }\end{array}$ & $\begin{array}{c}\text { Não se pode alegar que houve atuação } \\
\text { profissional entre a obtenção do diploma e o } \\
\text { debut na política }\end{array}$ & $\begin{array}{c}\text { Tempo inferior a quatro } \\
\text { anos entre a formação e a } \\
\text { entrada na política }\end{array}$ \\
\hline Advogados & $\begin{array}{c}\text { Tiveram atuação profissional sobretudo como } \\
\text { advogados }\end{array}$ & \\
\hline Juristas & $\begin{array}{c}\text { Atuaram profissionalmente, além da advocacia, } \\
\text { em outras áreas jurídicas }\end{array}$ & \multirow{2}{*}{$\begin{array}{c}\text { Tempo superior a quatro } \\
\text { anos entre a formação e a } \\
\text { entrada na política }\end{array}$} \\
\cline { 1 - 2 } Bacharéis & $\begin{array}{c}\text { "Advogado" consta em biografias como } \\
\text { profissão exercida, mas suas carreiras } \\
\text { profissionais sugerem predominância de } \\
\text { ocupações em outras áreas não relacionadas à } \\
\text { advocacia }\end{array}$ & \begin{tabular}{c} 
\\
\hline
\end{tabular} \\
\hline
\end{tabular}

FONTE: Adaptada de ALMEIDA (2016).

Foi feita uma Análise de Correspondência Simples entre o posicionamento ideológico do partido do advogado-deputado analisado e seu tipo de trajetória profissional, uma vez que se acredita fortemente que determinadas carreiras são inclinadas a alguns posicionamentos ideológicos específicos.

Em seguida, estas variáveis foram confrontadas com outras, que se relacionam ao fato de o indivíduo possuir ou não atuação na Câmara em posições de destaque ("alto clero"), ao número de cargos prévios que teve - sendo "muitos" acima de 5 e "poucos" até 2 cargos - e, novamente, à sua ideologia. Tais variáveis assim são apresentadas para que seja testada a hipótese de que aspectos políticos de uma trajetória individual estão relacionados a aspectos profissionais. A categorização dos partidos no espectro ideológico obedeceu à seguinte lógica:

TABELA 2 - CLASSIFICAÇÃO DE PARTIDOS CONFORME SEU POSICIONAMENTO NO ESPECTRO IDEOLÓGICO

\begin{tabular}{c|c|c}
\hline & $\mathbf{1 9 4 5 - 1 9 6 2}$ & $\mathbf{1 9 8 6 - 2 0 1 0}$ \\
\hline Esquerda & PST, MTR, PRT & PT, PPS, PDT, PSB, PRT \\
\hline Centro & PSD, PTB, PTN, MPA, PSP, & PSDB, PMDB, PST \\
\hline Direita & UDN, PRP, PR & $\begin{array}{c}\text { PDS, PPR, PSC, PFL, DEM, PDC, } \\
\text { PTB, PSD, PTC, PRN, PSL, PR }\end{array}$ \\
\hline
\end{tabular}

FONTE: A autora (2016).

O método aqui utilizado, a Análise de Correspondência Múltipla, não só encontra as relações entre essas variáveis e o tipo de exercício profissional prévio dos políticos, como

\footnotetext{
${ }^{5}$ Sendo integrantes do "alto clero" aqueles que foram líderes de bancadas partidárias e suprapartidárias, membros titulares da mesa diretora, presidentes de comissões permanentes e líderes de frentes parlamentares (SIMONI; MUCINHATO; MINGARDI, 2015) e do "baixo clero" todos os demais.
} 
também apresenta as relações internas a elas: todas as variáveis estarão em um mesmo nível, num teste que busca as relações entre elas.

\section{METODOLOGIA: UMA BREVE EXPLICAÇÃO SOBRE A ANÁLISE DE CORRESPONDÊNCIA MULTIVARIADA, SEUS USOS, SEU PROCESSO DE CONSTRUÇÃO E SEU MODO DE INTERPRETAÇÃO}

A Análise de Correspondência Multivariada (doravante ACM) é um método não linear de análise, que integra ideias em escala multidimensional, ao mesmo tempo em que é uma técnica gráfica que minimiza distâncias entre pontos conectados em um plano (GREENACRE, 2010; HOFFMAN; DE LEEUW, 1992). Neste processo, variáveis categóricas são quantificadas de modo a receberem valores numéricos para suas categorias, organizando seus pontos num plano onde objetos de uma mesma categoria pareçam mais próximos entre si, enquanto aqueles de categorias distintas parecem distantes (MEULMAN; HEISER, 2004). Podemos considerar esse método como próximo de uma Análise de Componentes Principais para variáveis categóricas, ou de uma escala métrica multidimensional para matrizes de cruzamento de dados: um método de análise nos quais dados tabulados e suas frequências podem ser representados graficamente (GREENACRE, 2007).

Com a formação de clusters ou agrupamentos de características relacionadas, é possível que exista material para uma análise tipológica, uma vez que teríamos conjuntos de categorias mutuamente excludentes ou de ocorrência exclusiva quando acompanhadas de outras determinadas características. Este trabalho se utiliza de normalização simétrica, uma vez que a variância é dada de forma bem-distribuída entre as linhas e colunas da matriz que origina o padrão da análise.

\section{PRIMEIRO ASPECTO DE ANÁlISE: CORRESPONDÊNCIA ENTRE TIPO DE EXERCÍCIO PROFISSIONAL PRÉVIO E IDEOLOGIA PARTIDÁRIA}

Serão exibidas as Análises de Correspondência referentes a "tipo de exercício profissional" versus “ideologia" para os recortes de 1945 a 1962 e de 1986 a 2010, respectivamente, para investigação e comparação: 


\section{FIGURA 1 - ANÁLISE DE CORRESPONDÊNCIA ENTRE TIPO DE EXERCÍCIO PROFISSIONAL E IDEOLOGIA PARTIDÁRIA (1945-1962)}

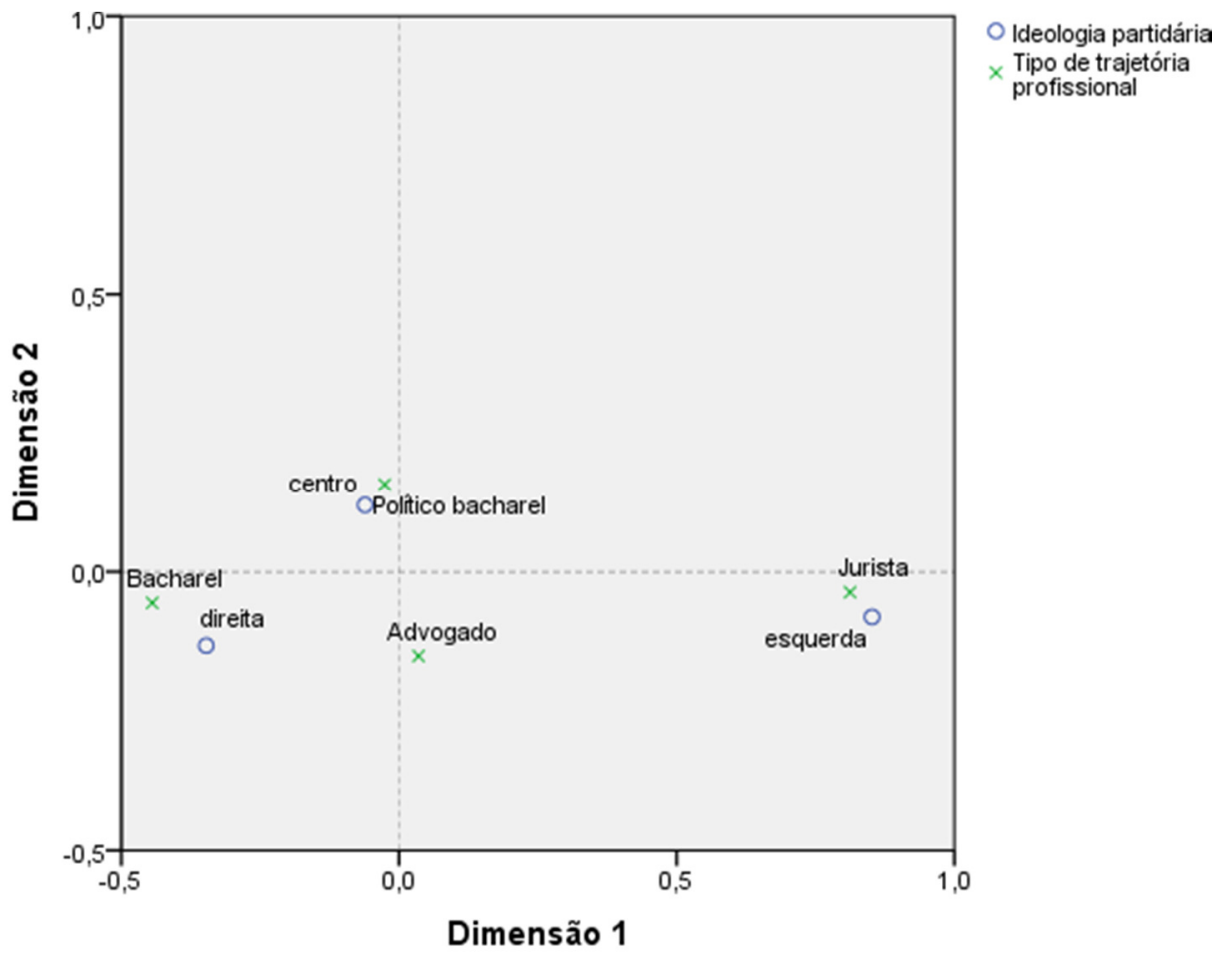

$\mathrm{N}=249$. Gráfico de pontos de categoria gerado em normalização simétrica. Tem-se aqui que a Dimensão 1 é responsável por 99,3\% da variância total do modelo. Índice de variância total (inertia) de 0,028. Qui-quadrado= FONTE: NUSP/UFPR (2016). 7,059. Sig. $=0,315$ (6 d.f.)

Como observação preliminar, é possível dizer que os "políticos bacharéis" estão próximos a um posicionamento centrista, enquanto aqueles portadores de "capital adicional" ("bacharéis") se encontram mais próximos à direita. Os advogados "puros" se dividem entre a direita e o centro, estando um pouco mais afastados da esquerda, que "traz para si" o ponto relativo àqueles que exerceram profissões jurídicas. A proximidade entre centro e direita nos aponta que as profissões próximas a estes pontos podem, inclusive, serem consideradas intercambiáveis.

Em números, temos que a esquerda tem uma proporção maior de juristas do que de outros posicionamentos, sendo aqueles $27,9 \%$ dos seus quadros, contra $11,9 \%$ da direita e $15,6 \%$ do centro. Da mesma forma, $29,3 \%$ dos juristas são parte da esquerda, contra $18 \%$ dos "advogados puros", 10,8\% dos de profissões mistas ("bacharéis") e 16,7\% dos "políticos bacharéis". Isso quer dizer que a maioria dos juristas não é de esquerda e que a maioria dos indivíduos de esquerda não é jurista - sobretudo porque ambos os grupos são subrepresentados —, mas que a proporção de juristas na esquerda é superior à de outras combinações de profissão e aspecto ideológico. 
Para o recorte temporal entre 1986 e 2010, temos o seguinte plano de análise:

\section{FIGURA 2 - ANÁLISE DE CORRESPONDÊNCIA ENTRE TIPO DE EXERCÍCIO PROFISSIONAL E IDEOLOGIA PARTIDÁRIA (1986-2010)}

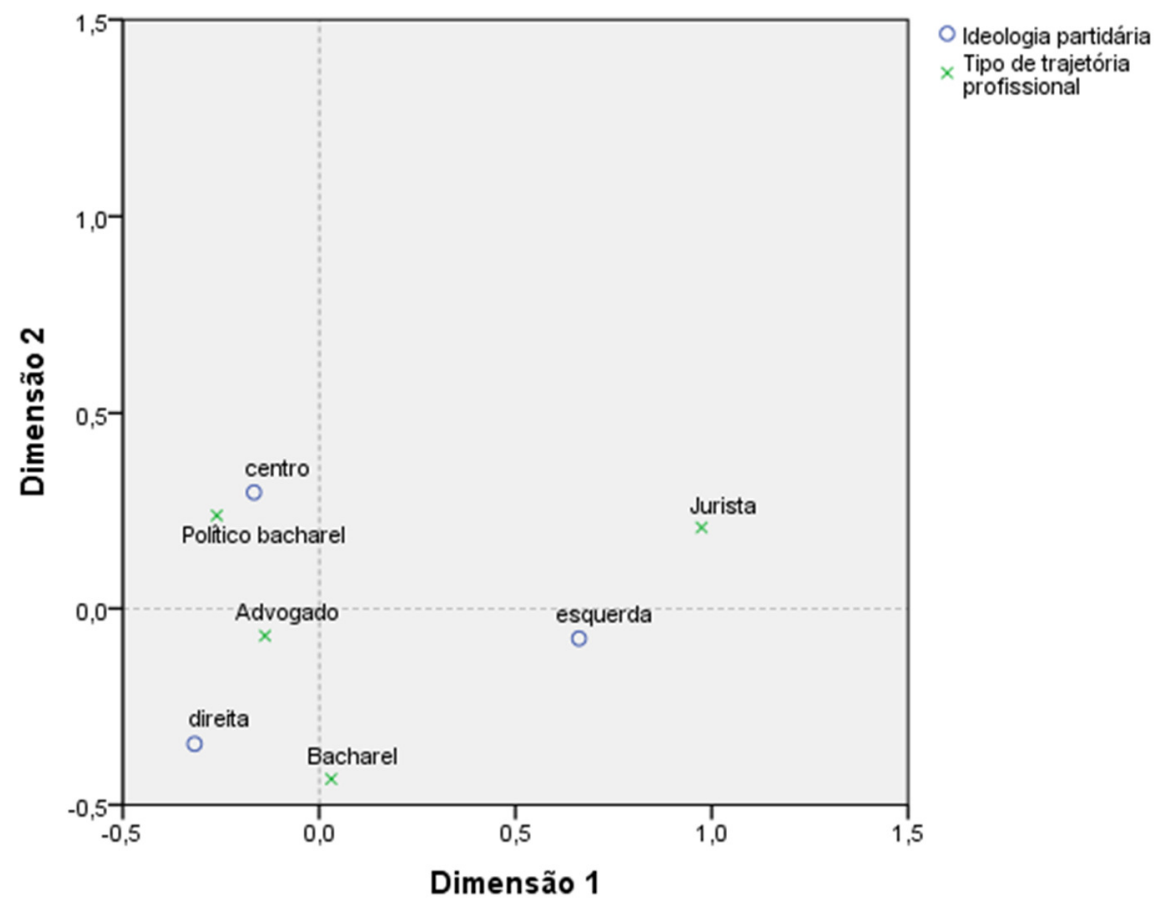

$\mathrm{N}=237$. Gráfico de pontos de categoria gerado em normalização simétrica. A Dimensão 1 é responsável por $80,7 \%$ da variância total do modelo e a Dimensão 2, por 19,3\%. Índice de variância total (inertia) de 0,03. QuiFONTE: NUSP/UFPR (2016). quadrado $=7,149$. Sig. $=0,307$ (6 d.f.)

As relações entre ideologia e trajetória profissional são observadas numa disposição muito semelhante à do quadro anterior. No entanto, embora os juristas tendam a ser de esquerda, a esquerda não necessariamente será ligada aos juristas. O centro se aproxima mais dos "bacharéis políticos", os "advogados puros" se dividem sobretudo entre centro e direita e a direita é vista tanto entre aqueles que têm a advocacia como "capital adicional" ("bacharéis") quanto pelos "advogados puros". No entanto, a proximidade desses pontos do centroide (coordenadas $\mathrm{x} 0, \mathrm{y} 0$ ) indica que o centro e a direita frequentemente se recombinam de diversas formas no que diz respeito aos "bacharéis", "políticos bacharéis" e "advogados".

Buscando especificidades, 41,9\% dos analisados considerados juristas são de esquerda, enquanto $21,3 \%$ daqueles de esquerda são juristas, em contraste com $8,1 \%$ dos de direita e $11,8 \%$ do centro. Assim, preferencialmente, os juristas são de esquerda — mas não necessariamente aqueles de esquerda são juristas. 


\section{RESULTADOS PARA TODOS OS PERÍODOS ESTUDADOS CONJUNTAMENTE: ANÁLISE DE CORRESPONDÊNCIA MÚLTIPLA}

Aqui, apresentamos, por tópico de análise e por ordem de output, todos os períodos analisados: primeiramente, aquele entre 1945 e 1962 e, posteriormente, o de 1986 a 2010.

Inicialmente, temos um Alfa de Cronbach $^{6}$ médio de 0,301 para ambos os recortes valor este considerado muito baixo e indicando uma alta heterogeneização dos dados. No entanto, por ser uma pesquisa de caráter descritivo, será considerado um achado por si só a heterogeneidade do modelo: toda combinação de características possível está presente no meio analisado. No entanto, a ocorrência de determinadas combinações não é inteiramente aleatória e é possível a observação de "tendências" quanto à ocorrência de dadas características e ao pertencimento a determinadas categorias.

Das correlações encontradas, a extensão da carreira política do indivíduo analisado apresentou estar ligada ao tipo de trajetória profissional exercida previamente à política. As demais aproximações e afastamentos de categorias podem ser vistas a seguir:

\section{FIGURA 3 - ANÁLISE DE CORRESPONDÊNCIA MÚLTIPLA PARA O RECORTE 1945-1962}

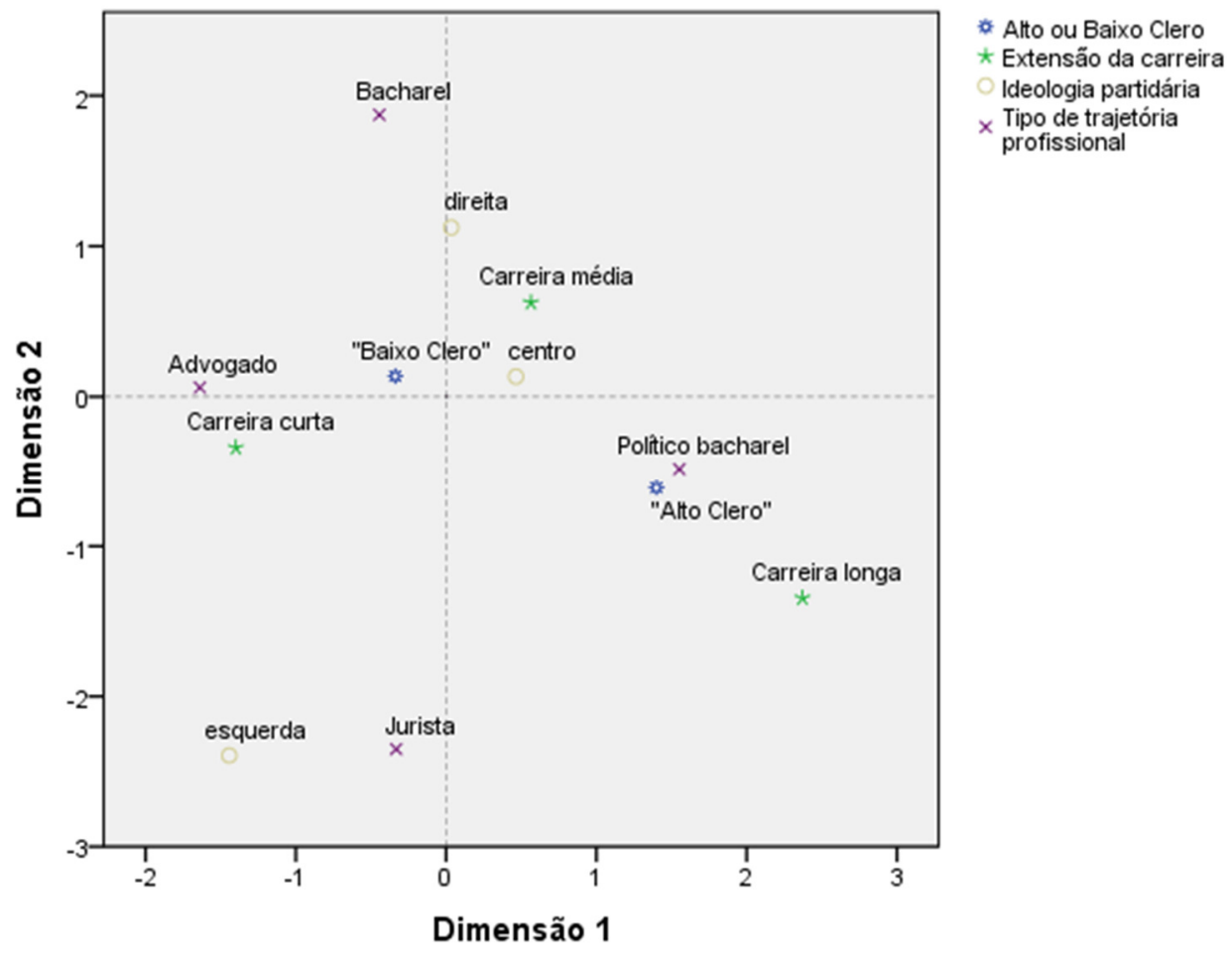

\footnotetext{
${ }^{6}$ O Alfa de Cronbach pode ser considerado uma "medida de consistência interna" - quanto maior seu valor, maior a probabilidade de que os objetos analisados formem grupos coesos segundo suas características. Um Alfa de Cronbach considerado "baixo" (abaixo de 0,500) indica que as categorias se recombinam de diversas formas e de que o seu modelo é heterogêneo.
} 
$\mathrm{N}=249$. Gráfico de pontos de categoria gerado em normalização simétrica. A Dimensão 1 é responsável por $34,7 \%$ da variância total do modelo e a Dimensão 2, por 29,8\% — de um total de índice de inertia de 0,646.

FONTE: NUSP/UFPR (2016). Variância média de $32,3 \%$.

Começando a análise pelo centroide, temos que os grupos mais indiferenciados (ou seja, de perfil mais diversificado) são o do "baixo clero" e o dos advogados-deputados do centro ideológico. O “alto clero" se aproxima dos "políticos bacharéis" e daqueles de carreiras longas, indicando uma ascensão em postos da Câmara para aqueles de entrada precoce na política e de longa trajetória dentro dela. As carreiras consideradas curtas se aproximam daqueles que chamamos "advogados puros", enquanto as médias se aproximam dos "bacharéis" (que exerceram outras profissões).

Assim, pensando o último e mais recente recorte, temos a Figura 4:

\section{FIGURA 4 - ANÁLISE DE CORRESPONDÊNCIA MÚLTIPLA PARA O PERÍODO 1986-2010}

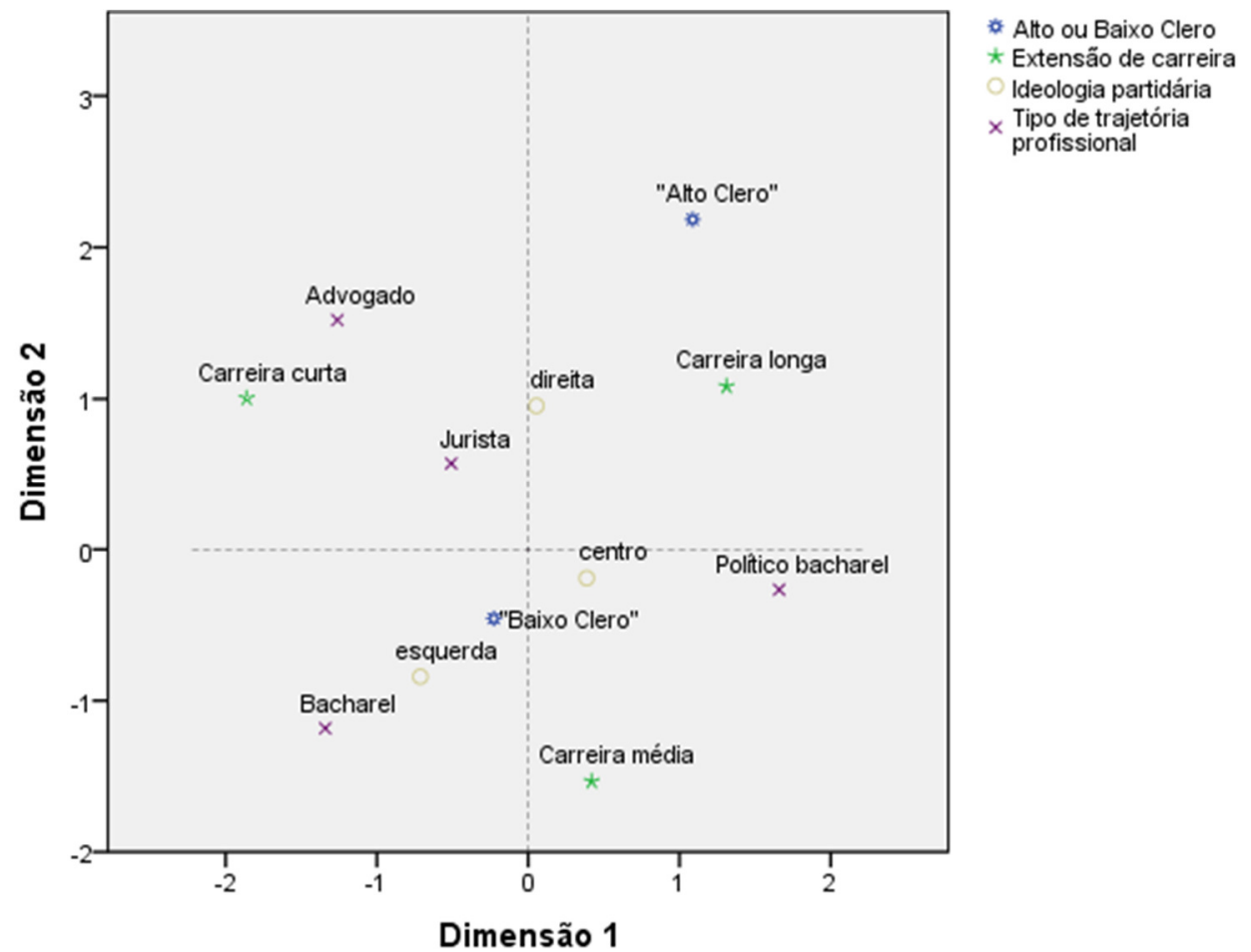

$\mathrm{N}=237$. Gráfico de pontos de categoria gerado em normalização simétrica. A Dimensão 1 é responsável por $33,63 \%$ da variância total do modelo e a Dimensão 2, por 30,294\% — de um total de índice de inertia de 0,637.

FONTE: NUSP/UFPR (2016).

Variância média de $31,828 \%$.

Neste último quadro temos ao centro o "baixo clero" e o centro, conforme esperado, por possuírem perfil muito variado. Os "políticos bacharéis" se dividem entre carreiras médias e longas, enquanto os "advogados puros" estão mais próximos das carreiras curtas. Os "juristas" 
se dividem entre carreiras curtas e longas, se afastando das consideradas médias. O "alto clero" se relaciona a carreiras longas, porém não de maneira exclusiva: podemos interpretar que o "alto clero" exige carreiras longas, mas tê-las não é garantia de que se faz parte da categoria. A esquerda e o centro são as categorias ideológicas mais próximas do "baixo clero", sendo a direita a mais próxima do "alto clero".

\section{CONCLUSÕES}

Podemos dizer que os quadros de características são muito semelhantes em ambos os períodos estudados, sobretudo quando ligamos a ideologia ao meio profissional. Isso indica que, apesar de a profissão da advocacia não ter as mesmas formas e práticas ao longo do tempo, algumas inclinações permanecem quando relacionados o título profissional e aspectos políticos. $\mathrm{O}$ valor do título pode ter sua mudança observada quando relacionamos este trabalho àqueles que dizem respeito a um aumento de variedade de backgrounds sociais na política, mas, no caso deste trabalho, percebe-se que, além deste suposto valor, o mais importante numa carreira política é ser político acima de tudo - ou seja, o grupo profissional de maiores carreiras e posições de destaque não pode ser considerado somente como tal, e sim como portadores de certo "rótulo" social, sem vínculo prático com tal titulação.

As profissões jurídicas parecem estar, em sua maior proporção, nas esquerdas, e os "bacharéis políticos", por sua vez, estão inclinados a carreiras mais longas e postos de prestígio, comprovando que aquele que se dedica à política precocemente tende a nela permanecer por mais tempo, independentemente de qualquer pormenor a respeito de seu exercício profissional.

Da mesma forma, existe na esquerda uma maior proporção daqueles que têm a lei como ofício em mais de uma variedade, estando tal comprometimento provavelmente ligado a um envolvimento com questões sociais variadas, quando existe um engajamento no meio público. No caso dos "profissionais mistos", presentes em todos os posicionamentos no espectro ideológico, tem-se que, para alguns, o título adicional dado pela advocacia é algo desejável para a construção de uma carreira política, sobretudo considerando-se aqueles que jamais chegaram a exercer a profissão.

A oposição "mais político" versus "mais profissional" nos traz questões a serem desenvolvidas em estudos envolvendo outros meios profissionais, embora se adiante a impressão de que o "título de advogado" é útil para a construção de carreiras políticas mesmo quando dissociado de uma carreira real, o que possivelmente não se observaria em outras 
profissões. No entanto, esta é uma especulação que deve ser melhor explorada em trabalhos seguintes.

\section{REFERÊNCIAS}

ALMEIDA, F. de. A nobreza togada: as elites jurídicas e a política da justiça no Brasil. São Paulo: Universidade de São Paulo, 2010a.

Inherited Capital and Acquired Capital: the Socio-political Dynamics of Producing Legal Elites. Brazilian Political Science Review, v. 4, n. 2, p. 32-59, 2010 b.

Os juristas e a política no Brasil: permanências e reposicionamentos. Lua Nova: Revista de Cultura e Política, n. 97, p. 213-250, abr. 2016.

BARMAN, R.; BARMAN, J. The Role of the Law Graduate in the Political Elite of Imperial Brazil. Journal of Inter-American Studies and World Affairs, v. 18, n. 4, p. 423-450, 1976.

BONELLI, M. D. G. As disputas em torno da fronteira entre profissão e política no Ministério Público Paulista. Novos Estudos - CEBRAP, n. 65, p. 169-182, 2003.

BOURDIEU, P. A representação política: elementos para uma teoria do campo político. In: . O poder simbólico. 2. ed. Rio de Janeiro: Bertrand Brasil, 1998. p. 163-207.

. Espaço social e gênese das classes. In: O poder simbólico. 15 . ed. Rio de

Janeiro: Bertrand Brasil, 2011. p. 133-161.

CARVAlHO, J. M. de. Political Elites and State Building: the Case of Nineteenth-Century Brazil. Comparative Studies in Society and History, v. 24, n. 3, p. 378-399, 1982.

. A Construção da Ordem/Teatro de Sombras. [S.1.: s.n.], 2008.

CODATO, A.; COSTA, L. D.; MASSIMO, L. Classificando ocupações prévias à entrada na política: uma discussão metodológica e um teste empírico. Opinião Pública, v. 20, n. 3, p. 346-362, 2014.

DEZALAY, Y.; GARTH, B. A dolarização do conhecimento técnico profissional e do Estado: processos transnacionais e questões de legitimação na transformação do Estado, 1960-2000. Revista Brasileira de Ciências Sociais, v. 15, n. 43, p. 163-176, 2000.

DOGAN, M. Les professions propices à la carrière politique: osmoses, filières et viviers. In: OFFERLÉ, M. (Ed.). La profession politique: XIXe-XXe siècles. 1. ed. Paris: Belin, 1999. p. 171-199.

EULAU, H.; SPRAGUE, J. D. Lawyers in Politics: a Study in Professional Convergence. 1. ed. [S.1.:] Bobbs-Merrill Company, 1964.

GREENACRE, M. Correspondence Analysis in Practice. 2. ed. Barcelona: Chapman \& Hall: CRC, 2007. 
Correspondence Analysis Biplots. In: Biplots in Practice. 1. ed. [S.1.:]

Fundación BBVA, 2010. p. 78-88.

HOFFMAN, D. L.; DE LEEUW, J. Interpreting Multiple Correspondence Analysis as a Multidimensional Scaling Method. Marketing Letters, v. 3, n. 3, p. 259-272, 1992.

KARPIK, L. Avocat: une nouvelle profession? Revue française de Sociologie, v. 26, n. 4, p. 571-600, 1985.

MEULMAN, J. J.; HEISER, W. J.; SPSS. SPSS Categories 13.0. [S.1.: s. n.], 2004.

OFFERLÉ, M. Professions et profession politique. In: (Ed.). La profession politique: XIXe-XXe siècles. Paris: Belin, 1999. p. 7-35.

PARSONS, T. Las prefesiones y la estructura social. In: Ensayos de teoría sociológica. 1. ed. Buenos Aires: Paidós, 1967. p. 34-46.

PERISSINOTTO, R. M.; MIRÍADE, A. Caminhos para o parlamento: candidatos e eleitos nas eleições para deputado federal em 2006. Dados, v. 52, n. 2, p. 301-333, 2009.

RODRIGUES, L. M. Mudanças na classe política brasileira. São Paulo: Publifolha, 2006.

SADEK, M. T. Judiciário: mudanças e reformas. Estudos Avançados, v. 18, n. 51, p. 79-101, 2004.

SADEK, M. T.; DANTAS, H. Os bacharéis em Direito na reforma do judiciário: técnicos ou curiosos? São Paulo em Perspectiva, v. 14, n. 2, p. 101-111, 2000.

SIMONI, S.; MUCINHATO, R.; MINGARDI, L. O perfil biográfico do "alto clero" da Câmara dos Deputados no Brasil (1995-2010). [S.1.: s. n.], 2015.

VENANCIO, A. Das arcadas ao bacharelismo. 2. ed. São Paulo: Editora Perspectiva, 2004. 